\title{
COMMUNICABLE DISEASES REPORT, NEW SOUTH WALES, FOR JULY AND AUGUST 2005
}

For updated information, including data and facts on specific diseases, visit www.health.nsw.gov.au and click on Infectious Diseases.

\section{TRENDS}

Tables 2 and 3 and Figure 1 show reports of communicable diseases received through to July and August 2005 in NSW.

Notably, there have been the seasonal winter declines in arboviral infections and salmonellosis, and increases in influenza and invasive pneumococcal disease. A weekly update on influenza activity can be found at: www.health. nsw.gov.au/infect/pdf/flureport.pdf.

Reports of meningococcal disease so far this winter have been less frequent than in previous winters. In NSW in June and July 2005, 20 cases were reported compared with 35 for the same period in 2004, 42 in 2003, and 50 in 2002. An analysis of the serogroups involved demonstrated that while there was some decline in cases caused by serogroup B ( 15 cases in 2005 compared with 20 in 2004, 23 in 2003, and 20 in 2002), a sharper decline has occurred in cases caused by the vaccine-preventable serogroup $C$ (one in 2005, compared with five in 2004, nine in 2003 and 12 in 2002). A biweekly update on meningococcal disease activity can be found at: www.health.nsw.gov.au/infect/ pdf/mening_update.pdf.

Reports of pertussis continue to increase, with 711 cases notified across the state in July. Reports of laboratoryconfirmed mumps have increased in 2005 (72 in NSW from January to July 2005) compared with previous years (64 for all of 2004 and 35 for 2003). Of the cases reported in the previous 12 months, the largest proportion has been among people (predominantly men) in their twenties and older adults (both sexes). No case of measles has been reported in NSW since a patient with onset in April 2005.

Data from the NSW Influenza Surveillance Program www.health.nsw.gov.au/infect/pdf/flureport.pdf show an increase in influenza in the late part of August. The program collects data from selected general practitioners, emergency departments and laboratories. Four outbreaks of influenza were reported among residents of aged care facilities in NSW in August. Each outbreak was located in a different area health service. Three of the outbreaks were due to influenza A and one to influenza B. In each outbreak, local public health unit staff were able to assist in the rapid diagnosis and provision of infection control recommendations and, where indicated, provide vaccination and anti-influenza medications to residents and staff at risk of infection. The outbreaks appeared to quickly subside. Further evaluation is pending.

\section{ENTERIC DISEASE}

The number of cases of cryptosporidiosis with onset dates in August 2005 declined $(n=25)$, when compared to previous months (83 in January, 42 in February, 62 in March, 118 in April, 96 in May, 54 in June, and 42 in July). However, the number of notifications with onset in August 2005 is greater than that reported for the previous four years (12 in 2004, six in 2003, eight in 2002, and nine in 2001). Since 1 May 2005, public health units have been following up cases of cryptosporidiosis to obtain information about potential exposures. As reported in a previous edition of the NSW Public Health Bulletin, the May 2005 outbreak was linked to swimming in contaminated pools. The increase in case reports may also be related to the introduction by some laboratories in 2004 of new testing procedures for cryptosporidiosis.

There was an increase in gastroenteritis outbreaks in aged care facilities and childcare centres reported by public health units in August, with norovirus and rotavirus identified as the causative agents in a number of outbreaks. This increase in gastroenteritis in institutions follows earlier reports of increases in diarrhoea and vomiting presentations at child emergency departments and subsequent increases in diarrhoea and vomiting presentations at adult emergency departments throughout August, identified through the Public Health Real-time Emergency Department Surveillance System. For example, for the week ending 21 August 2005, for the 17 participating emergency departments combined, there were 460 gastroenteritisrelated emergency department visits in that week compared with an average of 241 visits per week in the past 12 months. Of these, 76 per cent were in children, compared with a weekly average of 55 per cent in the past 12 months. Twenty nine per cent were admitted compared with an average of 31 per cent.

The protracted outbreak of Salmonella Typhimurium phage type 170/108 infections that began in November 2004 appears to have subsided, with only four cases notified with onset in August at the time this data was downloaded (6 September 2005).

\section{QUARTERLY REPORT: AUSTRALIAN CHILDHOOD IMMUNISATION REGISTER}

Table 1 compares the percentages of fully immunised Indigenous and non-Indigenous children in NSW aged 12 months to less than 15 months in each area health service, reported by all service providers as at 30 June 2005 and 30 September 2005.

These data refer to children whose age has been calculated 90 days before data extraction. The information contained in the report has been extracted from the Australian 
Childhood Immunisation Register (ACIR) and may be underestimated by approximately three per cent due to children being vaccinated late or to service providers failing to forward information to the ACIR. 圈

\section{TABLE 1}

COMPARISON OF PERCENTAGES OF FULLY IMMUNISED CHILDREN IN NSW AGED 12 MONTHS TO LESS THAN 15 MONTHS AS AT 30 JUNE 2005 AND 30 SEPTEMBER 2005, CATEGORIZED BY AREA HEALTH SERVICE AND BY INDIGENOUS AND NON-INDIGENOUS STATUS.

\begin{tabular}{|c|c|c|c|c|}
\hline \multirow[b]{2}{*}{ Area Health Service } & \multicolumn{2}{|c|}{30 June 2005} & \multicolumn{2}{|c|}{30 September 2005} \\
\hline & $\begin{array}{c}\text { Non-Indigenous } \\
\%\end{array}$ & $\begin{array}{c}\text { Indigenous } \\
\%\end{array}$ & $\begin{array}{c}\text { Non-Indigenous } \\
\%\end{array}$ & $\begin{array}{c}\text { Indigenous } \\
\%\end{array}$ \\
\hline Greater Southern & 93 & 91 & 93 & 88 \\
\hline Greater Western & 92 & 81 & 92 & 84 \\
\hline Hunter / New England & 94 & 87 & 93 & 82 \\
\hline North Coast & 83 & 83 & 85 & 78 \\
\hline Northern Sydney / Central Coast & 91 & 92 & 91 & 96 \\
\hline South Eastern Sydney / Illawarra & 90 & 91 & 90 & 83 \\
\hline Sydney South West & 90 & 83 & 90 & 83 \\
\hline Sydney West & 90 & 93 & 90 & 90 \\
\hline NSW & 91 & 87 & 91 & 85 \\
\hline AUSTRALIA & 91 & 85 & 91 & 85 \\
\hline
\end{tabular}

\section{ERRATA}

In the May-June 2005 issue of the NSW Public Health Bulletin (Volume 16, Number 5-6) there is an error on page 80 in Table 1: Disease notifications by year of onset of illness, NSW, 1991 to 2004. The number of new HIV infections for 1993 should read 586 , not 56 . This error has been corrected in the web versions of this issue.

In the July-August 2005 issue of the Bulletin (Volume 16 , Number 7-8) there is an error in the table on page 139: Table 2, Reports of notifiable conditions received in May 2005 by Area Health Service. The column headings SES and ILL (under South Eastern Syd/lllawarra) should be transposed. The same error appears in the table on page 140: Table 3, Reports of notifiable conditions received in June 2005 by Area Health Service. This error has been corrected in the web versions of this issue.

We apologise for any confusion these errors may have caused. 
FIGURE 1

REPORTS OF SELECTED COMMUNICABLE DISEASES, NSW, JAN 2000 TO AUG 2005, BY MONTH OF ONSET

Preliminary data: case counts in recent months may increase because of reporting delays.

Laboratory-confirmed cases only, except for measles, meningococcal disease and pertussis $\mathrm{BFV}=$ Barmah Forest virus infections,

RRV = Ross River virus infections

Lab conf $=$ laboratory confirmed
Men Gp C and Gp B = meningococcal disease due to serogroup $C$ and serogroup $B$ infection, other/unk = other or unknown serogroups.

NB: multiple series in graphs are stacked, except gastroenteritis outbreaks.

NB: Outbreaks are more likely to be reported by nursing homes and hospitals than by other institutions

\begin{tabular}{lr}
\hline \multicolumn{2}{|l|}{ NSW population } \\
Male & $50 \%$ \\
$<5$ yrs & $7 \%$ \\
$5-24$ yrs & $27 \%$ \\
$25-64$ yrs & $53 \%$ \\
$65+$ yrs & $13 \%$ \\
Rural & $46 \%$
\end{tabular}

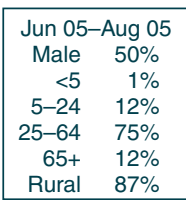

Rural $87 \%$
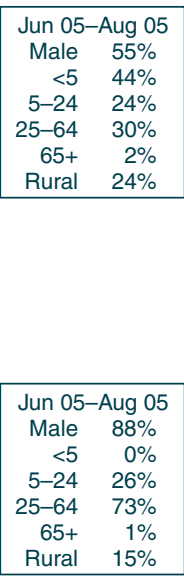

Jun 05-Aug 05 All outbreaks 14 Nursing homes Hospitals Child care

Schools

Other

\begin{tabular}{|cc|}
\hline \multicolumn{2}{|c|}{ Jun 05-Aug 05 } \\
Male & $52 \%$ \\
$<5$ & $4 \%$ \\
$5-24$ & $48 \%$ \\
$25-64$ & $48 \%$ \\
$65+$ & $0 \%$ \\
Rural & $13 \%$ \\
\hline
\end{tabular}

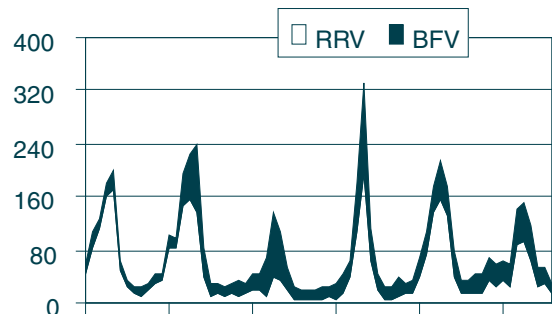

Arbovirus
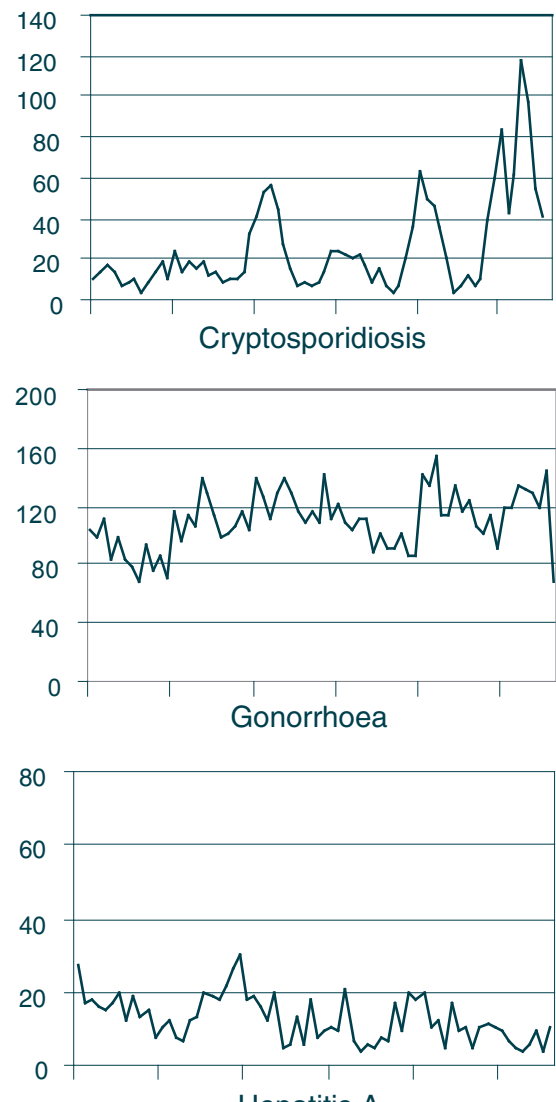

Hepatitis A

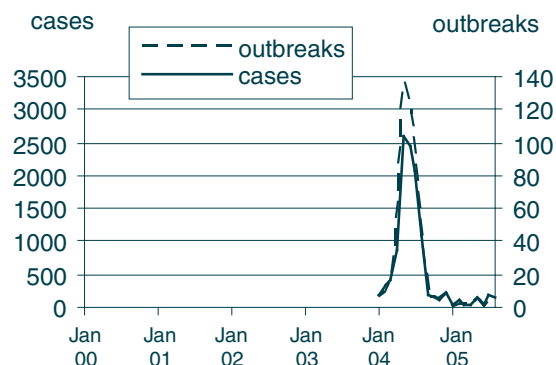

Gastroenteritis outbreaks in institutions

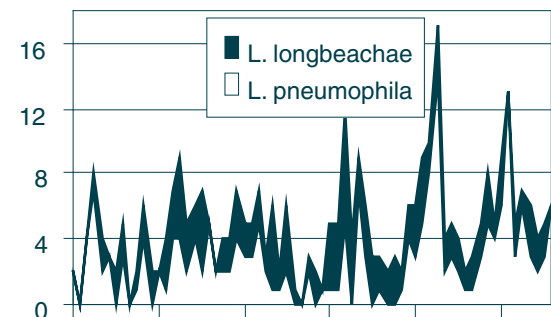

Jun 05-Aug 05 Male $\quad 60 \%$ \begin{tabular}{rr}
$<5$ & $0 \%$ \\
\hline
\end{tabular} 5-24 $0 \%$ 25-64 53\%

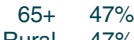

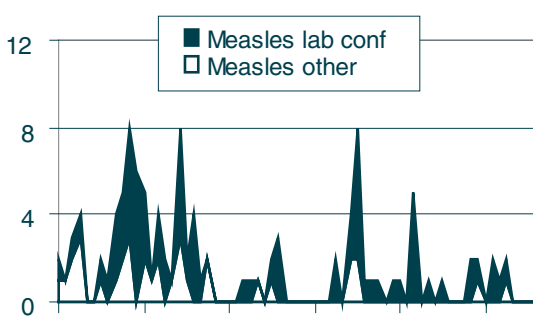

\begin{tabular}{|rc|}
\hline \multicolumn{2}{|c|}{ Jun 05-Aug 05 } \\
Male & $0 \%$ \\
$<5$ & $0 \%$ \\
$5-24$ & $0 \%$ \\
$25-64$ & $0 \%$ \\
$65+$ & $0 \%$ \\
Rural & $0 \%$ \\
\hline
\end{tabular}

Measles

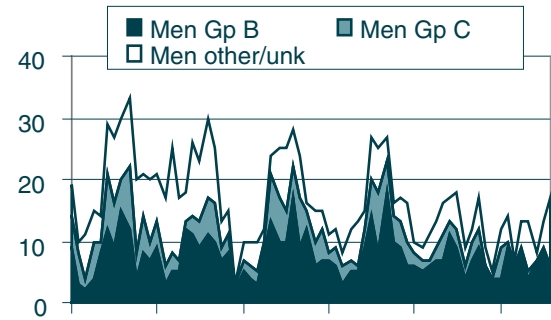

Meningococcal disease

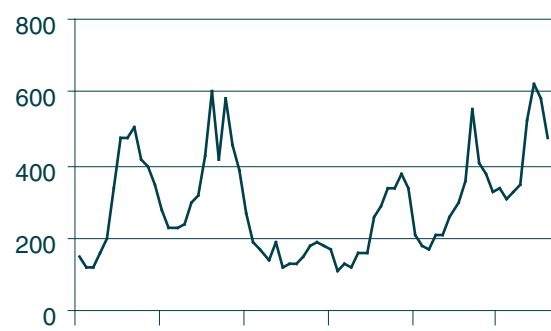

Jun 05-Aug 05 Male $41 \%$

$<5 \quad 4 \%$ $15 \%$ $65+\quad 12 \%$ Rural $31 \%$

Pertussis

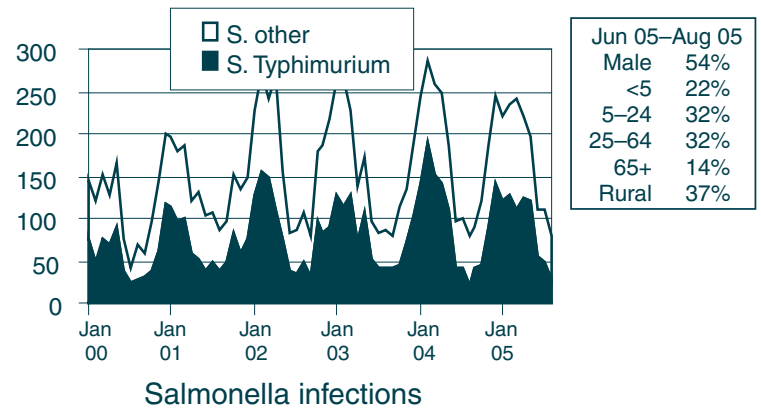




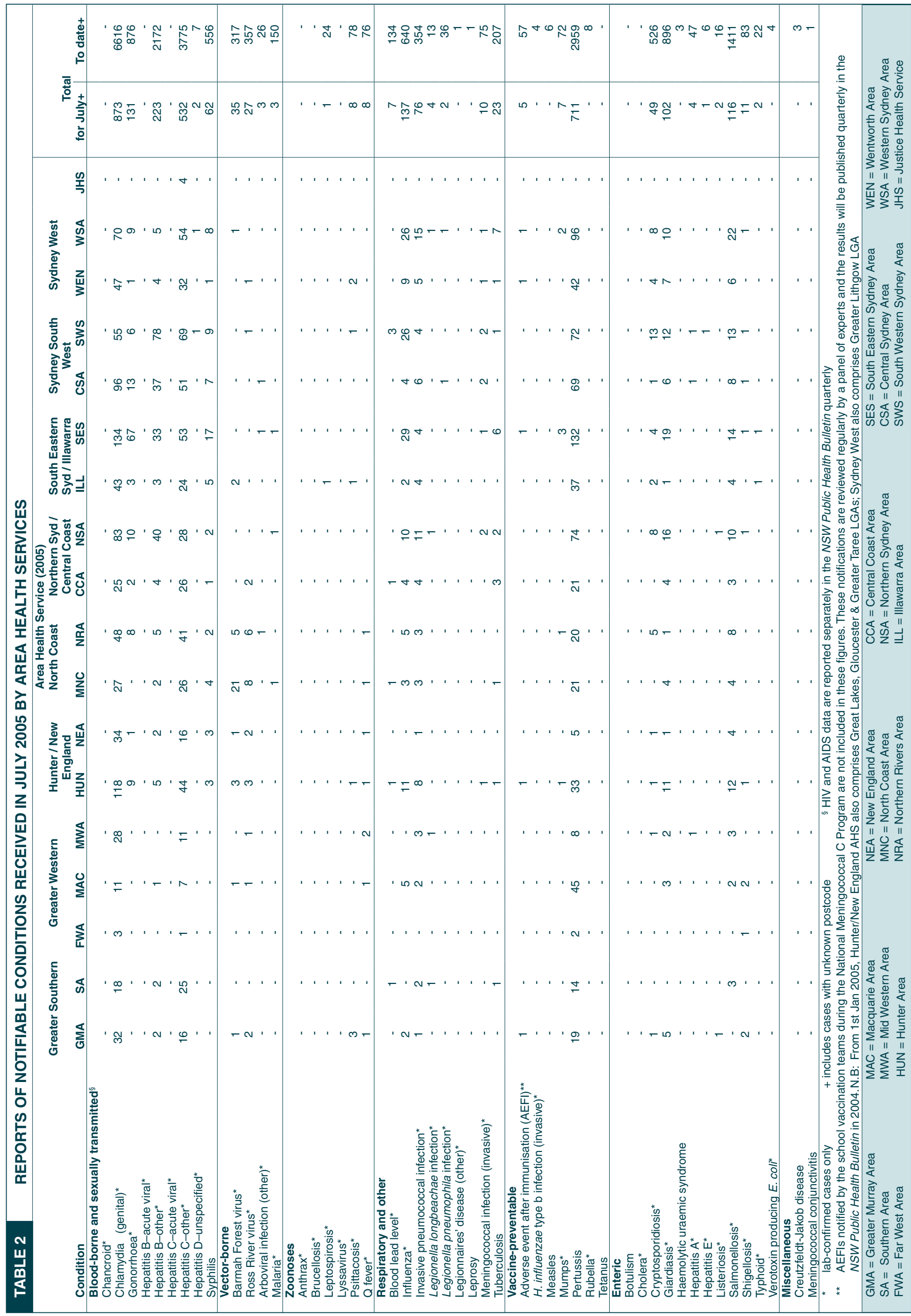




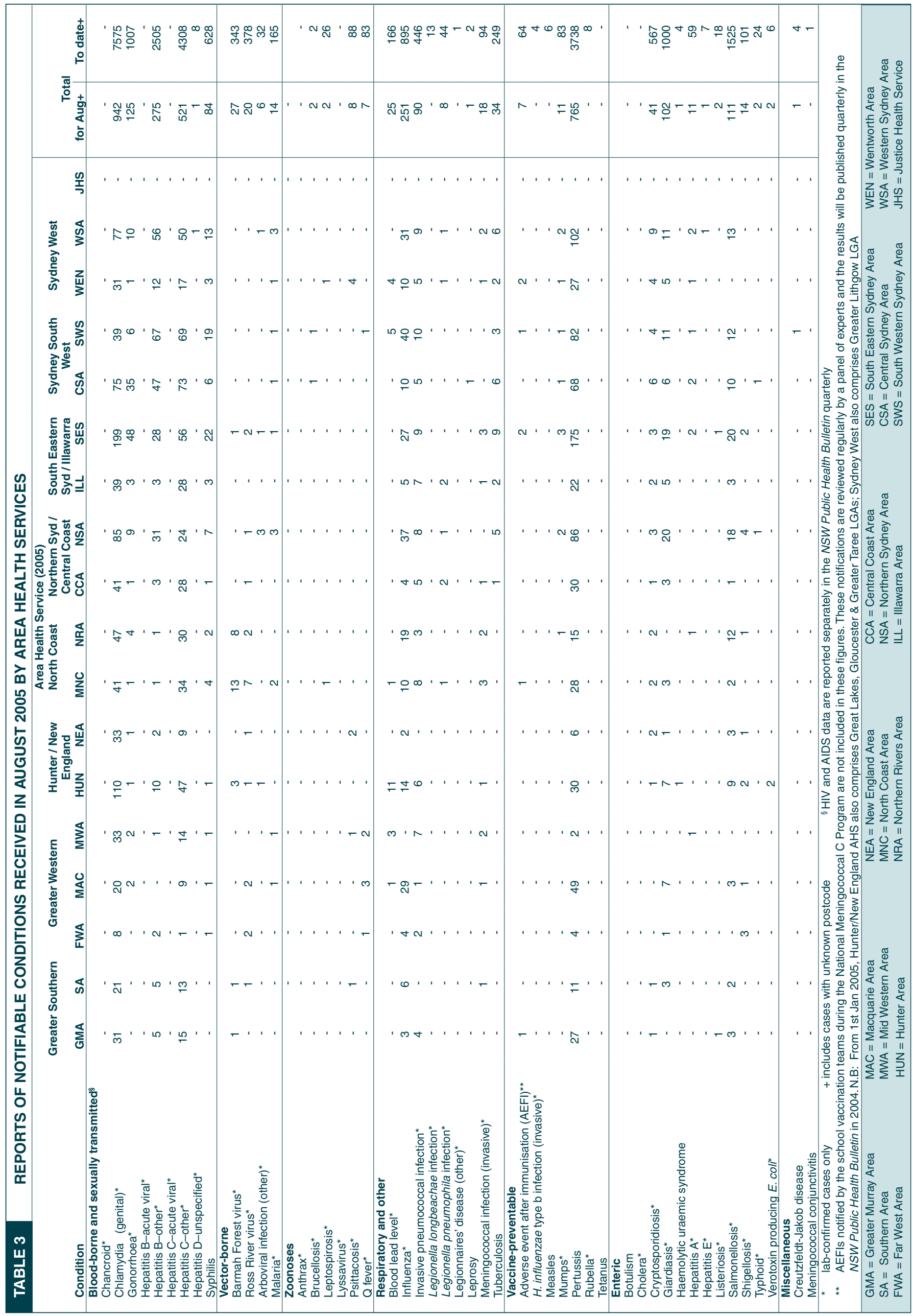

